\title{
Equilibrium between Fluorite and Pyrochlore Structures in the $\mathrm{ZrO}_{2}-\mathrm{Nd}_{2} \mathrm{O}_{3}$ System
}

\author{
Hiroshi Ohtani ${ }^{1,5}$, Satoshi Matsumoto ${ }^{2}$, Bo Sundman ${ }^{3}$, Taketo Sakuma ${ }^{4}$ and Mitsuhiro Hasebe ${ }^{1,5}$ \\ ${ }^{1}$ Department of Materials Science and Engineering, Kyushu Institute of Technology, Kitakyushu 804-8550, Japan \\ ${ }^{2}$ Graduate School, Kyushu Institute of Technology, Kitakyushu 804-8550, Japan \\ ${ }^{3}$ Department of Materials Science and Engineering, The Royal Institute of Technology, Stockholm 10044, Sweden \\ ${ }^{4}$ National Institution for Academic Degrees and University Evaluation, Tokyo 187-8587, Japan \\ ${ }^{5}$ CREST, Japan Science and Technology Agency
}

The phase diagram of the $\mathrm{ZrO}_{2}-\mathrm{Nd}_{2} \mathrm{O}_{3}$ system has been characterized showing isolated two-phase regions for a cubic fluorite-type $\mathrm{ZrO} 2$ solid solution and $\mathrm{Nd}_{2} \mathrm{Zr}_{2} \mathrm{O}_{7}$ with a pyrochlore-type structure. A thermodynamic analysis was carried out to elucidate the origin of this interesting phase equilibrium. A compound energy model with the formula $\left(\mathrm{Zr}^{4+}, \mathrm{Nd}^{3+}\right)_{0.5}\left(\mathrm{Nd}^{3+}, \mathrm{Zr}^{4+}\right)_{0.5}\left(\mathrm{O}^{2-}, \mathrm{va}\right)_{2}$ was applied to describe the Gibbs energy for these phases in consideration of the ordering of the cation sites in the structure. The ordering arrangement on the anion sites was not taken into account. The Gibbs energy for the liquid was described using an ionic solution model, while the binary compounds, such as tetragonal and monoclinic $\mathrm{ZrO}_{2}$, and cubic and hexagonal $\mathrm{Nd}_{2} \mathrm{O}_{3}$, were treated as stoichiometric solid phases. The thermodynamic assessment was based on the experimental phase boundaries as well as the evaluated formation energy for the stoichiometric $\mathrm{Nd}_{2} \mathrm{Zr}_{2} \mathrm{O}_{7}$ phase. The phase diagram calculations showed that the peculiar feature of this phase diagram was reproduced well in our work. The results strongly suggest that the two-phase boundaries between the cubic fluorite-type $\mathrm{ZrO}_{2}$ solid solution and the pyrochlore-type structure occur due to the ordering of the $\mathrm{Zr}^{4+}$ and $\mathrm{Nd}^{3+}$ cations.

(Received December 21, 2004; Accepted February 15, 2005; Published June 15, 2005)

Keywords: thermodynamic analysis, calculation of phase diagrams (CALPHAD) method, order-disorder transition, pyrochlore structure, zirconia ceramics

\section{Introduction}

Zirconia $\left(\mathrm{ZrO}_{2}\right)$ is widely utilized because it is an extremely strong and tough ceramic material. Its resistance to thermal shock is rather poor, however, due to the large change in volume that occurs during the phase transition from the monoclinic to the tetragonal form. The addition of a small amount of various oxides to $\mathrm{ZrO}_{2}$, such as $\mathrm{Y}_{2} \mathrm{O}_{3}, \mathrm{La}_{2} \mathrm{O}_{3}$, and other rare-earth oxides, stabilizes the cubic phase by lowering the transition temperature of the phase change, and consequently provides the material with improved thermal shock resistance. Various experimental studies on the phase relationships between $\mathrm{ZrO}_{2}$ and representative sesquioxides have been carried out, but information on the $\mathrm{ZrO}_{2}-\mathrm{Nd}_{2} \mathrm{O}_{3}$ phase diagram is rather limited. ${ }^{1,2}$

Figure 1 shows an experimental phase diagram of the $\mathrm{ZrO}_{2}-\mathrm{Nd}_{2} \mathrm{O}_{3}$ pseudo-binary system obtained using hightemperature X-ray analysis. ${ }^{1)} \mathrm{Cubic} \mathrm{ZrO}_{2}$ is stabilized in the low-temperature range upon the addition of $\mathrm{Nd}$, but further enrichment with $\mathrm{Nd}_{2} \mathrm{O}_{3}$ leads to the appearance of the pyrochlore structure. This phase diagram illustrates a characteristic feature of the $\mathrm{ZrO}_{2}-\mathrm{Nd}_{2} \mathrm{O}_{3}$ system; namely, the existence of an isolated two-phase region consisting of a cubic phase and a pyrochlore phase in the higher temperature region. Khanna et al. ${ }^{3)}$ performed Monte Carlo simulations on the $\mathrm{ZrO}_{2}-\mathrm{LnO}_{1.5}$ system within the framework of the 3D Ising model, and suggested that cation ordering occurs in the cubic phase stability region. We carried out a thermodynamic assessment of the $\mathrm{ZrO}_{2}-\mathrm{Nd}_{2} \mathrm{O}_{3}$ system based on the Calculation of Phase Diagrams (CALPHAD) approach to elucidate the origin of this interesting phase equilibrium.

\section{Thermodynamic Analysis of the $\mathrm{ZrO}_{2}-\mathrm{Nd}_{2} \mathrm{O}_{3}$ System}

\subsection{Experimental information on the $\mathrm{ZrO}_{2}-\mathrm{Nd}_{2} \mathrm{O}_{3}$ system}

Information on the phase relationships in the $\mathrm{ZrO}_{2}-\mathrm{Nd}_{2} \mathrm{O}_{3}$ system is quite limited. Brown and Duwez ${ }^{2)}$ investigated this system using X-ray diffraction and dilatometry. According to the proposed phase diagram, cubic $\mathrm{ZrO}_{2}$ is stable at temperatures above $T=1370^{\circ} \mathrm{C}$ upon the addition of $15-65 \mathrm{~mol} \%$ $\mathrm{Nd}_{2} \mathrm{O}_{3}$. Within this region, the coexistence of two cubic phases was found, based on measurements of the lattice parameters. The two-phase field extended from 40 to $60 \mathrm{~mol} \%$ in the temperature range of $1100-2100^{\circ} \mathrm{C}$. A eutectoid reaction between the two cubic phases and hexagonal $\mathrm{Nd}_{2} \mathrm{O}_{3}$ was arbitrarily located at $T=1100^{\circ} \mathrm{C}$ within the composition range of $40-90 \mathrm{~mol} \% \quad \mathrm{Nd}_{2} \mathrm{O}_{3}$. A eutectoid reaction between monoclinic, tetragonal, and cubic $\mathrm{ZrO}_{2}$ may occur below $T=567^{\circ} \mathrm{C}$. Monoclinic $\mathrm{ZrO}_{2}$ was assumed to have a maximum homogeneity region of about $3 \mathrm{~mol}_{\%} \mathrm{Nd}_{2} \mathrm{O}_{3}$.

The first detailed study of the $\mathrm{ZrO}_{2}-\mathrm{Nd}_{2} \mathrm{O}_{3}$ system was carried out by Rouanet. ${ }^{1)} \mathrm{He}$ described the high-temperature phase relationships above $T=1800^{\circ} \mathrm{C}$ and the liquidus curve for this system using high-temperature $\mathrm{X}$-ray measurements and thermal analysis. The phase diagram deduced by Rouanet is shown in Fig. 1. The liquidus curve was obtained from the cooling curves using thermal analysis, while the solidus curve was estimated. To prevent any contamination, the measurements were carried out in air without the use of crucibles, and the temperature was measured using optical pyrometry. The phase relationships above $T=1800^{\circ} \mathrm{C}$ were observed using high-temperature X-ray diffraction employing a Re ribbon. The samples were premelted in air using a 


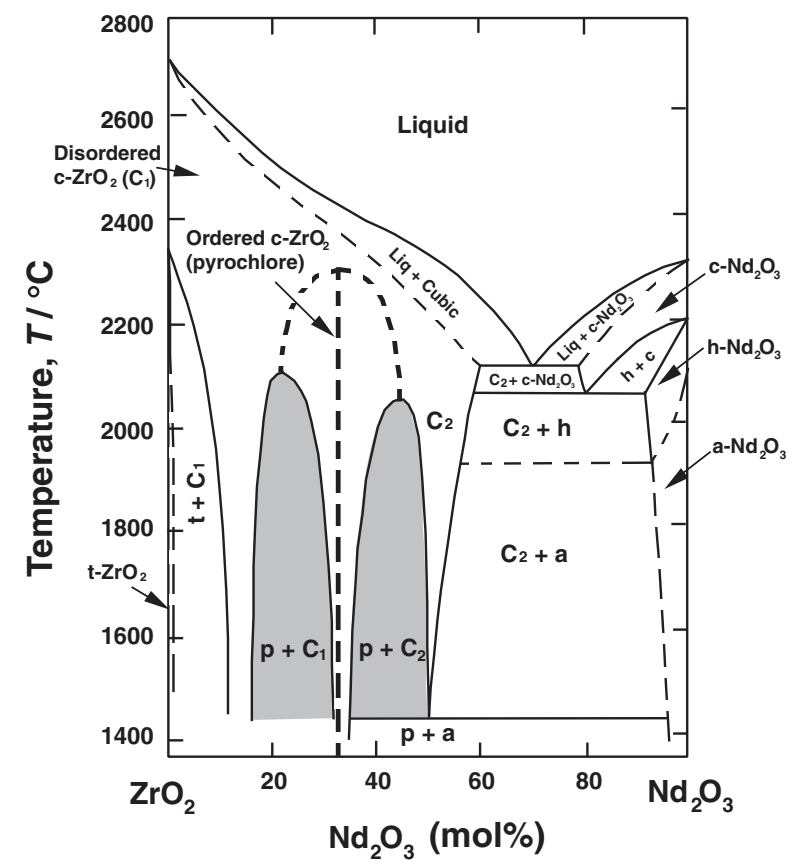

Fig. 1 Experimental phase diagram of the $\mathrm{ZrO}_{2}-\mathrm{Nd}_{2} \mathrm{O}_{3}$ pseudo-binary system. ${ }^{1)}$

solar furnace, then crushed and deposited on the heating element. The purity of the $\mathrm{ZrO}_{2}$ and $\mathrm{Nd}_{2} \mathrm{O}_{3}$ used as the starting materials was $99.9 \%$. Allotropic modification of the pure $\mathrm{Nd}_{2} \mathrm{O}_{3}$ from the cubic to the hexagonal structure was reported. However, the cubic phase was not obtained on quenching due to the high volatility of $\mathrm{Nd}_{2} \mathrm{O}_{3}$. The phase transition of the hexagonal solid solution denoted by $\mathrm{H} \rightarrow \mathrm{A}$ in Rouanet's work was not clearly defined, and consequently this was not taken into account in our study. In contrast to the results obtained by Brown and Duwez, ${ }^{2)}$ the formation of pyrochlore-type $\mathrm{Nd}_{2} \mathrm{Zr}_{2} \mathrm{O}_{7}$ at $33.3 \mathrm{~mol} \% \quad \mathrm{Nd}_{2} \mathrm{O}_{3}$ could be observed. This compound forms a two-phase region with cubic $\mathrm{ZrO}_{2}$ on both sides of the stoichiometric composition. The coexistence of two cubic structures in the composition range of $40-60 \mathrm{~mol} \% \mathrm{Nd}_{2} \mathrm{O}_{3}$, as reported by Brown and Duwez, possibly coincides with the two-phase field in the higher composition range.

With regard to the thermodynamic properties, a critical thermodynamic assessment of the $\mathrm{Zr}-\mathrm{O}$ binary system was performed by Liang et al. ${ }^{4}$ ) However, no thermodynamic description of the $\mathrm{ZrO}_{2}-\mathrm{Nd}_{2} \mathrm{O}_{3}$ system is available, except for the evaluated Gibbs energy of formation for the pyrochlore-type $\mathrm{Nd}_{2} \mathrm{Zr}_{2} \mathrm{O}_{7}$ phase. ${ }^{5)}$ In our thermodynamic analysis of the $\mathrm{ZrO}_{2}-\mathrm{Nd}_{2} \mathrm{O}_{3}$ system, the experimental phase boundaries obtained by Rouanet, ${ }^{1)}$ together with the estimated formation energy of the pyrochlore phase, ${ }^{5)}$ were analyzed using the thermodynamic models described in the following sections.

\subsection{Thermodynamic modeling}

According to the experimental $\mathrm{ZrO}_{2}-\mathrm{Nd}_{2} \mathrm{O}_{3}$ phase diagram, this system is composed of cubic $\mathrm{ZrO}_{2}\left(\mathrm{c}-\mathrm{ZrO}_{2}\right)$, tetragonal $\mathrm{ZrO}_{2}\left(\mathrm{t}-\mathrm{ZrO}_{2}\right)$, monoclinic $\mathrm{ZrO}_{2}\left(\mathrm{~m}-\mathrm{ZrO}_{2}\right)$, a pyrochlore solid solution $\left(\mathrm{Nd}_{2} \mathrm{Zr}_{2} \mathrm{O}_{7}\right)$, cubic $\mathrm{Nd}_{2} \mathrm{O}_{3}$ (c-
$\mathrm{Nd}_{2} \mathrm{O}_{3}$ ), hexagonal $\mathrm{Nd}_{2} \mathrm{O}_{3}$ (h- $\mathrm{Nd}_{2} \mathrm{O}_{3}$ ), and liquid phases. This section will describe the Gibbs energy for each phase that appears in the $\mathrm{ZrO}_{2}-\mathrm{Nd}_{2} \mathrm{O}_{3}$ system.

The Gibbs energy, ${ }^{\circ} G_{\mathrm{i}}$, of the pure element, i, as a function of the temperature, $T$, is described by the following equation:

$$
\begin{aligned}
{ }^{\circ} G_{\mathrm{i}}-{ }^{\circ} H_{\mathrm{i}}^{\mathrm{ref}}= & A+B T+C T \ln T+D T^{2} \\
& +E T^{3}+F T^{7}+I T^{-1}+J T^{-9},
\end{aligned}
$$

where ${ }^{\circ} H_{i}^{\text {ref }}$ denotes the molar enthalpy of the pure element $i$ in its stable state at $T=25^{\circ} \mathrm{C}$. The numerical values of the parameters used are the same as those published by Dinsdale, ${ }^{6)}$ as shown in Table 1.

\subsubsection{Cubic and pyrochlore structures}

Cubic $\mathrm{ZrO}_{2}$ has a fluorite-type structure, the tetragonal sites of which are fully occupied by oxygen anions, as shown in Fig. 2. This structure has space group Fm3m. On the other hand, the pyrochlore structure, $\mathrm{Nd}_{2} \mathrm{Zr}_{2} \mathrm{O}_{7}$, is composed of two types of octants, the I and II types, as illustrated in Fig. 3. A vacancy was introduced at each anion site of these octants due to the different ionic charges of $\mathrm{Zr}^{4+}$ and $\mathrm{Nd}^{3+}$. The vacancies were distributed one by one on each octant, and the pyrochlore structure, $\mathrm{Nd}_{2} \mathrm{Zr}_{2} \mathrm{O}_{7}$, was formed having a regular arrangement of the eight octants, as shown in Fig. 3. The space group of the pyrochlore structure is $\mathrm{Fd} \overline{3} \mathrm{~m}$.

In our thermodynamic analysis, we focused on the crystallographic similarity between these two structures. Figure 4 shows the atomic configuration of the pyrochlore unit cell, and that of the fluorite structure of the same size. (The oxygen atoms and the vacancies have been removed from these crystal cells). The ordering arrangement of the cations in the fcc lattice sites can be seen in the figure, and the phase change between the cubic and pyrochlore phases can be treated as being an order-disorder transition occurring in this fcc-based lattice.

We will now discuss a thermodynamic model suitable for describing the ordering behavior at the cation sites. Figure 5 shows the two types of octants in the pyrochlore structure arranged in rows. The fcc structure remains after the removal of the oxygen atoms and the vacancies from these octants. A subdivision of the fcc lattice sites into eight sublattices results in 13 types of superstructure. ${ }^{7)}$ These eight sublattices are represented by the Roman numerals in Fig. 5. Comparing this atomic arrangement with the sublattice definitions, the structure of the $\mathrm{Fd} \overline{3} \mathrm{~m}$ space group forms under the following sublattice constraint: $\mathrm{I}=\mathrm{II}=\mathrm{III}=\mathrm{IV}$ and $\mathrm{V}=\mathrm{VI}=$ VII = VIII. Therefore, to describe the ordering behavior of the cation sites between the cubic $\mathrm{ZrO}_{2}$ phase and the pyrochlore phase, the compound energy model, $\left(\mathrm{Zr}^{4+}\right.$, $\left.\mathrm{Nd}^{3+}\right)_{0.5}\left(\mathrm{Nd}^{3+}, \mathrm{Zr}^{4+}\right)_{0.5}\left(\mathrm{O}^{2-}, \mathrm{va}\right)_{2}$, was applied to these phases, assuming that tetravalent zirconium ions and trivalent neodymium ions exist on the two cation sublattices, and divalent oxygen ions and vacancies exist on the anion sublattice. The vacancies on the anion sublattice were introduced in all cases in order to maintain electroneutrality.

The Gibbs energy of the cubic and pyrochlore phases, $G_{\mathrm{m}}^{\mathrm{C}-\mathrm{P}}$, was expressed using the split compound energy formalism proposed by Ansara et al., ${ }^{8)}$ which separates the total Gibbs energy into a contribution from the disordered state and a contribution from the ordered state: 
Table 1 Lattice stability parameters for $\mathrm{Nd}, \mathrm{O}$, and $\mathrm{Zr}$.

\begin{tabular}{|c|c|c|c|c|c|}
\hline Element & Phase & $\begin{array}{l}\text { Lattice stability parameters } \\
\qquad(\mathrm{J} / \mathrm{mol})\end{array}$ & & $\begin{array}{l}\text { Temperature } \\
\left({ }^{\circ} \mathrm{C}\right)\end{array}$ & Reference \\
\hline \multirow[t]{4}{*}{$\mathrm{Nd}$} & \multirow[t]{4}{*}{ dhcp } & \multirow[t]{4}{*}{${ }^{\circ} G_{\mathrm{Nd}}^{\mathrm{dhcp}}-{ }^{\circ} H_{\mathrm{Nd}}^{\mathrm{dhcp}}$} & $\begin{aligned}= & -8402.93+111.10239 T-27.0858 T \ln T \\
& +5.56125 \times 10^{-4} T^{2}-2.6923 \times 10^{-6} T^{3}+34887 T^{-1}\end{aligned}$ & $25<T<627$ & \multirow[t]{4}{*}{ 4) } \\
\hline & & & $\begin{aligned}= & -6984.083+83.662617 T-22.7536 T \ln T \\
& -0.00420402 T^{2}-1.802 \times 10^{-6} T^{3}\end{aligned}$ & $627<T<855$ & \\
\hline & & & $\begin{aligned}= & -225610.846+1673.04075 T-238.182873 T \ln T \\
& +0.078615997 T^{2}-6.048207 \times 10^{-6} T^{3}+38810350 T^{-1}\end{aligned}$ & $855<T<1526$ & \\
\hline & & & $=-25742.331+276.257088 T-48.7854 T \ln T$ & $1526<T<1527$ & \\
\hline \multirow[t]{2}{*}{$\mathrm{O}$} & \multirow[t]{2}{*}{ gas } & \multirow[t]{2}{*}{${ }^{\circ} G_{\mathrm{O}}^{\mathrm{gas}}-{ }^{\circ} H_{\mathrm{O}}^{\mathrm{gas}}$} & $\begin{aligned}= & -3480.87-25.503038 T-11.136 T \ln T \\
& -0.0055098888 T^{2}+6.61846 \times 10^{-7} T^{3}-38365 T^{-1}\end{aligned}$ & $25<T<727$ & \multirow[t]{2}{*}{ 4) } \\
\hline & & & $\begin{aligned}= & -6568.763+12.65988 T-16.8138 T \ln T \\
& -5.95798 \times 10^{-4} T^{2}+6.781 \times 10^{-9} T^{3}+262905 T^{-1}\end{aligned}$ & $727<T<3027$ & \\
\hline \multirow[t]{4}{*}{$\mathrm{Zr}$} & \multirow[t]{2}{*}{ hcp } & \multirow[t]{2}{*}{${ }^{\circ} G_{\mathrm{Zr}}^{\mathrm{hcp}}-{ }^{\circ} H_{\mathrm{Zr}}^{\mathrm{hcp}}$} & $\begin{aligned}= & -7827.595+125.64905 T-24.1618 T \ln T \\
& -0.00437791 T^{2}+34971 T^{-1}\end{aligned}$ & $1027<T<1855$ & \multirow[t]{4}{*}{ 4) } \\
\hline & & & $\begin{aligned}= & -26085.921+262.724183 T \\
& -42.144 T \ln T-1.342895 \times 10^{31} T^{-9}\end{aligned}$ & $1855<T<5727$ & \\
\hline & \multirow[t]{2}{*}{$\mathrm{L}$} & \multirow[t]{2}{*}{${ }^{\circ} G_{\mathrm{Zr}}^{\mathrm{L}}-{ }^{\circ} G_{\mathrm{Zr}}^{\mathrm{hcp}}$} & $=18147.69-9.080812 T+1.6275 \times 10^{-22} T^{7}$ & $25<T<1855$ & \\
\hline & & & $=17804.661-8.911574 T+1.342895 \times 10^{31} T^{-9}$ & $1855<T<5727$ & \\
\hline
\end{tabular}
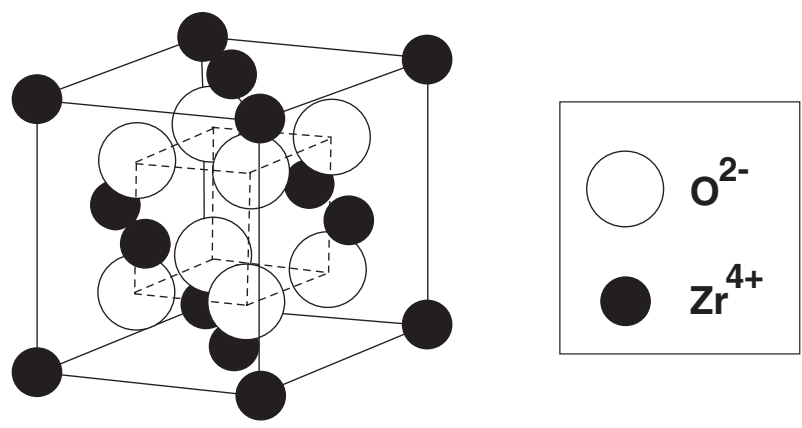

Fig. 2 Crystal structure of fluorite-type cubic $\mathrm{ZrO}_{2}$.
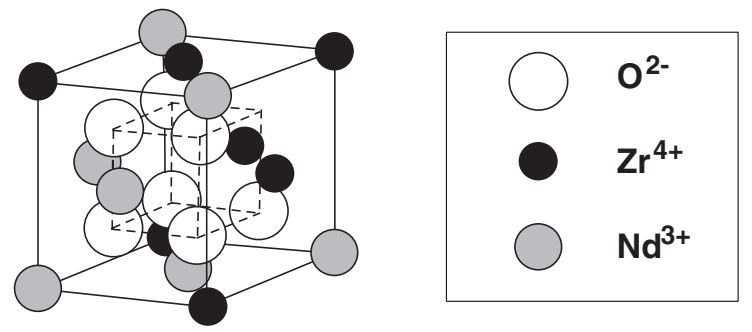

\section{I-type octant}
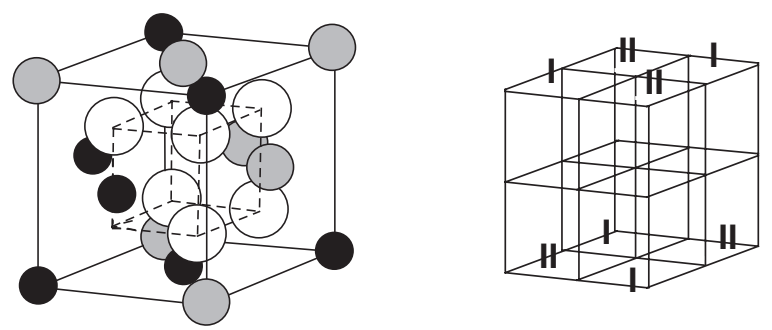

II-type octant

Pyrochlore structure

Fig. 3 The two types of octant in the pyrochlore structure.

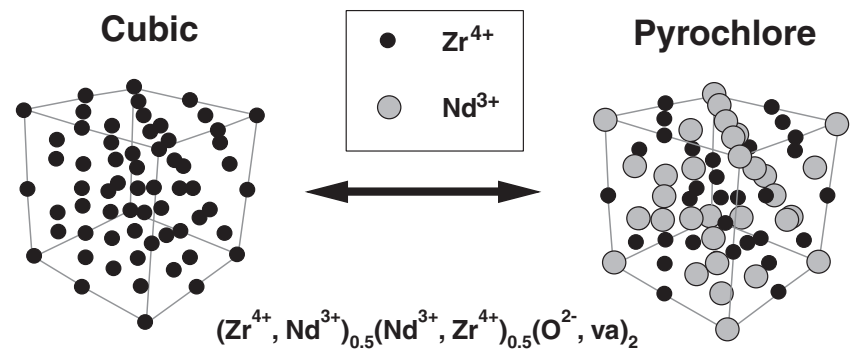

Fig. 4 Comparison of atomic arrangement in the unit cells of the pyrochlore structure and that in the fluorite structure of the same size. The oxygen atoms and vacancies are not shown in these structures.

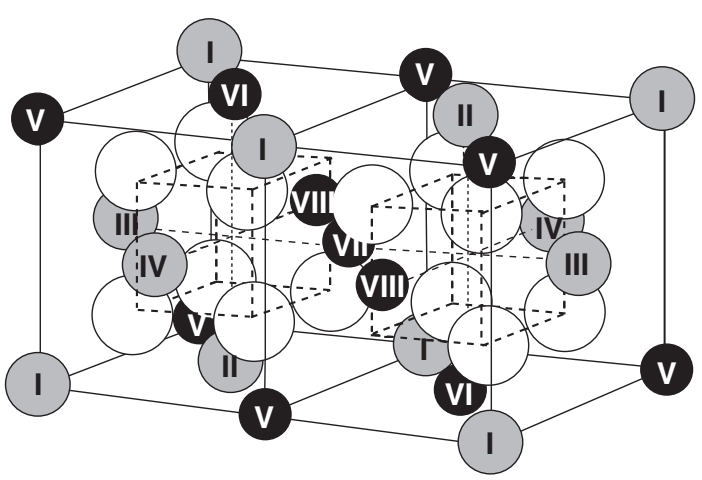

Fig. 5 Subdivision of the cation sites of the octants in the pyrochlore structure into sublattices.

$$
G_{\mathrm{m}}^{\mathrm{C}-\mathrm{P}}=G_{\mathrm{m}}^{\mathrm{dis}}+\Delta G_{\mathrm{m}}^{\mathrm{ord}},
$$

where $G_{\mathrm{m}}^{\mathrm{dis}}$ is the Gibbs energy of the disordered solution of the fundamental structure corresponding to the cubic structure $\left(\mathrm{Zr}^{4+}, \mathrm{Nd}^{3+}\right)_{1}\left(\mathrm{O}^{2-}, \mathrm{va}\right)_{2}$. This is described by 


$$
\begin{aligned}
G_{\mathrm{m}}^{\mathrm{dis}}= & y_{\mathrm{Nd}^{3+}}^{\prime} y_{\mathrm{O}^{2-}}^{\prime \prime}{ }^{\circ} G_{\mathrm{Nd}^{3+}: \mathrm{O}^{2-}}^{\mathrm{cub}}+y_{\mathrm{Zr}^{4+}}^{\prime} y_{\mathrm{O}^{2-}}^{\prime \prime} G_{\mathrm{Zr}^{4+}: \mathrm{O}^{2-}}^{\mathrm{cub}} \\
& +y_{\mathrm{Nd}^{3+}}^{\prime} y_{\mathrm{va}}^{\prime \prime} G_{\mathrm{Nd}^{3+}: \mathrm{va}}^{\mathrm{cub}}+y_{\mathrm{Zr}^{4+}}^{\prime} y_{\mathrm{va}}^{\prime \prime}{ }^{\circ} G_{\mathrm{Zr}^{+4}: \mathrm{va}}^{\mathrm{cub}} \\
& +R T\left(y_{\mathrm{Nd}^{3+}}^{\prime} \ln y_{\mathrm{Nd}^{3+}}^{\prime}+y_{\mathrm{Zr}^{4+}}^{\prime} \ln y_{\mathrm{Zr}^{4+}}^{\prime}\right) \\
& +2 R T\left(y_{\mathrm{O}^{2-}}^{\prime \prime} \ln y_{\mathrm{O}^{2-}}^{\prime \prime}+y_{\mathrm{va}}^{\prime \prime} \ln y_{\mathrm{va}}^{\prime \prime}\right) \\
& +y_{\mathrm{Nd}^{3+}}^{\prime} y_{\mathrm{Zr}^{4+}}^{\prime} y_{\mathrm{O}^{2-}} L_{\mathrm{Nd}}^{\mathrm{cug}}, \mathrm{Zr}^{4+}: \mathrm{O}^{2-} \\
& +y_{\mathrm{Nd}^{3+}}^{\prime} y_{\mathrm{Zr}^{4+}}^{\prime} y_{\mathrm{va}}^{\prime \prime} L_{\mathrm{Nd}^{3+}, \mathrm{Zr}^{4+}: \mathrm{va}}^{\mathrm{cub}} \\
& +y_{\mathrm{Nd}^{+3}}^{\prime} y_{\mathrm{O}^{2-}}^{\prime \prime} y_{\mathrm{va}}^{\prime \prime} L_{\mathrm{Nd}^{3+}: \mathrm{O}^{2-}, \mathrm{va}}^{\mathrm{cub}}+y_{\mathrm{Zr}^{4+}}^{\prime} y_{\mathrm{O}^{2-}}^{\prime \prime} y_{\mathrm{va}}^{\prime \prime} L_{\mathrm{Zr}^{4+}: \mathrm{O}^{2-}, \mathrm{va}}^{\mathrm{cub}}
\end{aligned}
$$

The parameter ${ }^{\circ} G_{\mathrm{Nd}^{3+}: \mathrm{O}^{2-}}^{\mathrm{cub}}$ is the molar Gibbs energy of the ideal hypothetical charged species, $\mathrm{Nd}_{1} \mathrm{O}_{2}^{1-}$. The parameter $L_{\mathrm{i}, \mathrm{j}: \mathrm{k}}^{\text {cub }}\left(\right.$ or $L_{\mathrm{i}: \mathrm{j}, \mathrm{k}}^{\mathrm{c}}$ ) denotes the interaction energy between unlike atoms on the same sublattice, and has a compositional dependency following the Redlich-Kister polynomial that can be expressed as

$$
\begin{aligned}
L_{\mathrm{i}, \mathrm{j}: \mathrm{k}}^{\mathrm{cub}}= & { }^{0} L_{\mathrm{i}, \mathrm{j}: \mathrm{k}}^{\mathrm{cub}}+{ }^{1} L_{\mathrm{i}, \mathrm{j}: \mathrm{k}}^{\mathrm{cub}}\left(y_{\mathrm{i}}^{\prime}-y_{\mathrm{j}}^{\prime}\right)+{ }^{2} L_{\mathrm{i}, \mathrm{j}: \mathrm{k}}^{\mathrm{cub}}\left(y_{\mathrm{i}}^{\prime}-y_{\mathrm{j}}^{\prime}\right)^{2}+\cdots \\
& +{ }^{n} L_{\mathrm{i}, \mathrm{j}: \mathrm{k}}^{\mathrm{cub}}\left(y_{\mathrm{i}}^{\prime}-y_{\mathrm{j}}^{\prime}\right)^{n},
\end{aligned}
$$

where

$$
{ }^{n} L_{\mathrm{i}, \mathrm{j}: \mathrm{k}}^{\mathrm{cub}}=a+b T+c T \ln T+\mathrm{d} T^{2}+\cdots .
$$

The quantities $y_{\mathrm{i}}^{\prime}$ and $y_{\mathrm{j}}^{\prime \prime}$ are the site fractions of the elements $\mathrm{i}$ and $\mathrm{j}$ in their respective sublattices, which are designated by "'" and "'"”, respectively.

The ordering contribution to the Gibbs energy is expressed as

$$
\begin{aligned}
& \Delta G_{\mathrm{m}}^{\mathrm{ord}}=y_{\mathrm{Nd}^{3+}}^{(1)} y_{\mathrm{Nd}^{3+}}^{(2)} y_{\mathrm{O}^{2-}}^{(3)} G_{\mathrm{Nd}^{3+}: \mathrm{Nd}^{3+}: \mathrm{O}^{2-}}^{\mathrm{C}-\mathrm{P}} \\
& +y_{\mathrm{Nd}^{3+}}^{(1)} y_{\mathrm{Nd}^{3+}}^{(2)} y_{\mathrm{va}}^{(3) \circ} G_{\mathrm{Nd}^{3+}: \mathrm{Nd}^{3+}: \mathrm{va}}^{\mathrm{C}-\mathrm{P}} \\
& +y_{\mathrm{Zr}^{4+}}^{(1)} y_{\mathrm{Zr}^{4+}}^{(2)} y_{\mathrm{O}^{2-}}^{(3)}{ }^{\circ} G_{\mathrm{Zr}^{4+}: \mathrm{Zr}^{4+}: \mathrm{O}^{2-}}^{\mathrm{C}-\mathrm{P}} \\
& +y_{\mathrm{Zr}^{4+}}^{(1)} y_{\mathrm{Zr}^{4+}}^{(2)} y_{\mathrm{va}}^{(3) \circ} G_{\mathrm{Zr}^{4+}}^{\mathrm{C}-\mathrm{P}} \mathrm{Zr}^{4+}: \mathrm{va} \\
& +y_{\mathrm{Nd}^{3+}}^{(1)} y_{\mathrm{Zr}^{4+}}^{(2)} y_{\mathrm{O}^{2-}}^{(3)}{ }^{\circ} G_{\mathrm{Nd}^{3+}: \mathrm{Zr}^{4+}: \mathrm{O}^{2-}}^{\mathrm{C}-\mathrm{P}} \\
& +y_{\mathrm{Nd}^{3+}}^{(1)} y_{\mathrm{Zr}^{4+}}^{(2)} y_{\mathrm{va}}^{(3) \circ} G_{\mathrm{Nd}^{3+}: \mathrm{Zr}^{4+}: \mathrm{va}}^{\mathrm{C}-\mathrm{P}} \\
& +y_{\mathrm{Zr}^{4+}}^{(1)} y_{\mathrm{Nd}^{3+}}^{(2)} y_{\mathrm{O}^{2-}}^{(3)}{ }^{\circ} G_{\mathrm{Zr}^{4+}: \mathrm{Nd}^{3+}: \mathrm{O}^{2-}}^{\mathrm{C}-\mathrm{P}} \\
& +y_{\mathrm{Zr}^{4+}}^{(1)} y_{\mathrm{Nd}^{3+}}^{(2)} y_{\mathrm{va}}^{(3) \circ} G_{\mathrm{Zr}^{4+}: \mathrm{Nd}^{3+}: \mathrm{va}}^{\mathrm{C}-\mathrm{P}} \\
& +0.5 R T\left(y_{\mathrm{Nd}^{3+}}^{(1)} \ln y_{\mathrm{Nd}^{3+}}^{(1)}+y_{\mathrm{Zr}^{4+}}^{(1)} \ln y_{\mathrm{Zr}^{4+}}^{(1)}\right) \\
& +0.5 R T\left(y_{\mathrm{Nd}^{3+}}^{(2)} \ln y_{\mathrm{Nd}^{3+}}^{(2)}+y_{\mathrm{Zr}^{4+}}^{(2)} \ln y_{\mathrm{Zr}^{++}}^{(2)}\right) \\
& +2 R T\left(y_{\mathrm{O}^{2-}}^{(3)} \ln y_{\mathrm{O}^{2-}}^{(3)}+y_{\mathrm{va}}^{(3)} \ln y_{\mathrm{va}}^{(3)}\right) \\
& +y_{\mathrm{Nd}^{3+}}^{(1)} y_{\mathrm{Zr}^{4+}}^{(1)} y_{\mathrm{Nd}^{3+}}^{(2)} y_{\mathrm{O}^{2-}}^{(3)} L_{\mathrm{Nd}^{3+}, \mathrm{Zr}^{4+}: \mathrm{Nd}^{3+}: \mathrm{O}^{2-}}^{\mathrm{C}-\mathrm{P}} \\
& +y_{\mathrm{Nd}^{3+}}^{(1)} y_{\mathrm{Zr}^{4+}}^{(1)} y_{\mathrm{Nd}^{3+}}^{(2)} y_{\mathrm{va}}^{(3)} L_{\mathrm{Nd}^{3+}, \mathrm{Zr}^{4+}: \mathrm{Nd}^{3+}: \mathrm{va}}^{\mathrm{C}-\mathrm{P}} \\
& +y_{\mathrm{Nd}^{3+}}^{(1)} y_{\mathrm{Zr}^{4+}}^{(1)} y_{\mathrm{Zr}^{4+}}^{(2)} y_{\mathrm{O}^{2-}}^{(3)} L_{\mathrm{Nd}^{3+}, \mathrm{Zr}^{4+}: \mathrm{Zr}^{4+}: \mathrm{O}^{2-}}^{\mathrm{C}-\mathrm{P}} \\
& +y_{\mathrm{Nd}^{3+}}^{(1)} y_{\mathrm{Zr}^{4+}}^{(1)} y_{\mathrm{Zr}^{4+}}^{(2)} y_{\mathrm{va}}^{(3)} L_{\mathrm{Nd}^{3+}, \mathrm{Zr}^{4+}: \mathrm{Zr}^{4+}: \mathrm{va}}^{\mathrm{C}-\mathrm{P}} \\
& +y_{\mathrm{Nd}^{3+}}^{(1)} y_{\mathrm{Nd}^{3+}}^{(2)} y_{\mathrm{Zr}^{4+}}^{(2)} y_{\mathrm{O}^{2-}}^{(3)} L_{\mathrm{Nd}^{3+}: \mathrm{Nd}^{3+}, \mathrm{Zr}^{4+}: \mathrm{O}^{2-}}^{\mathrm{C}-\mathrm{P}} \\
& +y_{\mathrm{Nd}^{3+}}^{(1)} y_{\mathrm{Nd}^{3+}}^{(2)} y_{\mathrm{Zr}^{4+}}^{(2)} y_{\mathrm{va}}^{(3)} L_{\mathrm{Nd}^{3+}: \mathrm{Nd}^{3+}, \mathrm{Zr}^{4+}: \mathrm{va}} \\
& +y_{\mathrm{Zr}^{4+}}^{(1)} y_{\mathrm{Nd}^{3+}}^{(2)} y_{\mathrm{Zr}^{4+}}^{(2)} y_{\mathrm{O}^{2-}}^{(3)} L_{\mathrm{Zr}^{4+}: \mathrm{Nd}^{3+}, \mathrm{Zr}^{4+}: \mathrm{O}^{2-}}^{\mathrm{C}-\mathrm{P}} \\
& +y_{\mathrm{Zr}^{4+}}^{(1)} y_{\mathrm{Nd}^{3+}}^{(2)} y_{\mathrm{Zr}^{4+}}^{(2)} y_{\mathrm{va}}^{(3)} L_{\mathrm{Zr}^{4+}: \mathrm{Nd}^{3+}, \mathrm{Zr}^{4+}: \mathrm{va}}^{\mathrm{C}-\mathrm{P}} \\
& +y_{\mathrm{Nd}^{3+}}^{(1)} y_{\mathrm{Nd}^{3+}}^{(2)} y_{\mathrm{O}^{2-}}^{(3)} y_{\mathrm{va}}^{(3)} L_{\mathrm{Nd}^{3+}: \mathrm{Nd}^{3+}: \mathrm{O}^{2-}, \mathrm{va}}^{\mathrm{C}-\mathrm{P}} \\
& +y_{\mathrm{Nd}^{3+}}^{(1)} y_{\mathrm{Zr}^{4+}}^{(2)} y_{\mathrm{O}^{2-}}^{(3)} y_{\mathrm{va}}^{(3)} L_{\mathrm{Nd}^{3+}: \mathrm{Zr}^{4+}: \mathrm{O}^{2-}: \mathrm{va}}^{\mathrm{C}-\mathrm{P}}
\end{aligned}
$$

$$
\begin{aligned}
& +y_{\mathrm{Zr}^{4+}}^{(1)} y_{\mathrm{Nd}^{3+}}^{(2)} y_{\mathrm{O}^{2-}}^{(3)} y_{\mathrm{va}}^{(3)} L_{\mathrm{Zr}^{4+}: \mathrm{Nd}^{3+}: \mathrm{O}^{2-}, \mathrm{va}}^{\mathrm{C}-\mathrm{P}} \\
& +y_{\mathrm{Zr}^{4+}}^{(1)} y_{\mathrm{Zr}^{4+}}^{(2)} y_{\mathrm{O}^{2-}}^{(3)} y_{\mathrm{va}}^{(3)} L_{\mathrm{Zr}^{4+}: \mathrm{Zr}^{4+}: \mathrm{O}^{2-}, \mathrm{va}}^{\mathrm{C}-\mathrm{P}} \\
& +y_{\mathrm{Nd}^{3+}}^{(1)} y_{\mathrm{Zr}^{4+}}^{(1)} y_{\mathrm{Nd}^{3+}}^{(2)} y_{\mathrm{Zr}^{4+}}^{(2)} y_{\mathrm{O}^{2-}}^{(3)} L_{\mathrm{Nd}^{3+}, \mathrm{Zr}^{4+}: \mathrm{Nd}^{3+}, \mathrm{Zr}^{4+}: \mathrm{O}^{2-}}^{\mathrm{C}-\mathrm{P}} \\
& +y_{\mathrm{Nd}^{3+}}^{(1)} y_{\mathrm{Zr}^{4+}}^{(1)} y_{\mathrm{Nd}^{3+}}^{(2)} y_{\mathrm{Zr}^{4+}}^{(2)} y_{\mathrm{va}}^{(3)} L_{\mathrm{Nd}^{3+}, \mathrm{Zr}^{4+}: \mathrm{Nd}^{3+}, \mathrm{Zr}^{4+}: \mathrm{va}}^{\mathrm{C}-\mathrm{P}}
\end{aligned}
$$

where $y_{i}^{(\mathrm{n})}$ is the site fraction of element $\mathrm{i}$ on the (n) sublattice

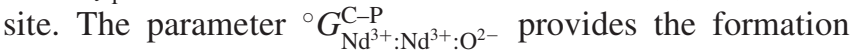
energy of a fictitious compound having all the cation sites filled with $\mathrm{Nd}^{3+}$ ions and the anion sites occupied by $\mathrm{O}^{2-}$ ions. This energy should be identical to that of the ${ }^{\circ} G_{\mathrm{Nd}^{3+}: \mathrm{O}^{2-}}^{\mathrm{cub}}$ term in eq. (3) in the completely disordered cation configuration, where $y_{\mathrm{Nd}^{3+}}^{(1)}=y_{\mathrm{Nd}^{3+}}^{(2)}=y_{\mathrm{Nd}^{3+}}^{\prime}$, and therefore, ${ }^{\circ} G_{\mathrm{Nd}^{3+}: \mathrm{Nd}^{3+}: \mathrm{O}^{2-}}^{\mathrm{C}-\mathrm{was}}$ set to zero in the description of eq. (6).

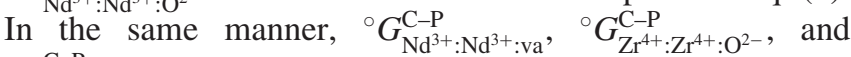
${ }^{\circ} G_{\mathrm{Zr}^{4+}: \mathrm{Zr}^{4+} \text { :va }}^{\mathrm{C}-\mathrm{P}}$ were all set to zero. Furthermore, due to the lack of experimental data for determining all the thermodynamic parameters, assumptions, such as ${ }^{\circ} G_{\mathrm{Nd}^{3+}: \mathrm{Zr}^{4+}: \mathrm{O}^{2-}}^{\mathrm{C}-\mathrm{P}}=$ ${ }^{\circ} G_{\mathrm{Zr}^{4+}: \mathrm{Nd}^{3+}: \mathrm{O}^{2-}}^{\mathrm{C}}={ }^{\circ} G_{\mathrm{Nd}^{3+}: \mathrm{Zr}^{4+}: \mathrm{va}}^{\mathrm{C}}={ }^{\circ} G_{\mathrm{Zr}^{4+}: \mathrm{Nd}^{3+}: \mathrm{va}}^{\mathrm{C}}$, were introduced for the sake of simplicity. For the same reason, an assumption of $L_{\mathrm{Nd}^{3+}, \mathrm{Zr}^{4+}: *: *}^{\mathrm{C}-\mathrm{P}}=L_{*: \mathrm{Nd}^{3+}, \mathrm{Zr}^{4+}: *}^{\mathrm{C}}$, where the asterisk denotes that the parameter is independent of the constituents of a specific sublattice, was applied to the regular solution interaction parameters. The term $L_{\mathrm{Nd}^{3+}, \mathrm{Zr}^{4+}: \mathrm{Nd}^{3+}, \mathrm{Zr}^{4+}: *}^{\mathrm{C}}$ is the socalled reciprocal interaction parameter.

\subsubsection{Liquid phase}

When two basic oxides are mixed in the liquid state, the Gibbs energy can be represented by the ionic two-sublattice model $^{9)}$ by mixing the cations on one sublattice and completely filling the other sublattice with $\mathrm{O}^{2-}$ ions. For the $\mathrm{ZrO}_{2}-\mathrm{Nd}_{2} \mathrm{O}_{3}$ system, this situation is realized using the formula $\left(\mathrm{Nd}^{3+}, \mathrm{Zr}^{4+}\right)_{\mathrm{P}}\left(\mathrm{O}^{2-}\right)_{\mathrm{Q}}$. The ions within each parenthesis form a sublattice, and the site ratios are denoted by $\mathrm{P}$ and Q. These parameters are composition dependent, and are calculated to maintain electroneutrality in the liquid phase using the following equations:

$$
\mathrm{P}=2 y_{\mathrm{O}^{2-}}^{(2)}=2, \quad \mathrm{Q}=3 y_{\mathrm{Nd}^{3+}}^{(1)}+4 y_{\mathrm{Zr}^{4+}}^{(1)} .
$$

These relationships mean that the values of $\mathrm{P}$ and $\mathrm{Q}$ are equivalent to the average charge on the other sublattice.

The integral Gibbs energy for the liquid phase based on this model is then given by

$$
\begin{aligned}
G_{\mathrm{m}}^{\mathrm{L}}= & y_{\mathrm{Nd}^{3+}}^{(1)} G_{\mathrm{Nd}^{3+}: \mathrm{O}^{2-}}^{\mathrm{L}}+y_{\mathrm{Zr}^{4+}}^{(1)} G_{\mathrm{Zr}^{4+}: \mathrm{O}^{2-}}^{\mathrm{L}} \\
& +2 R T\left(y_{\mathrm{Nd}^{3+}}^{(1)} \ln y_{\mathrm{Nd}^{3+}}^{(1)}+y_{\mathrm{Zr}^{4+}}^{(1)} \ln y_{\mathrm{Zr}^{4+}}^{(1)}\right) \\
& +y_{\mathrm{Nd}^{3+}}^{(1)} y_{\mathrm{Zr}^{4+}}^{(1)} L_{\mathrm{Nd}^{3+}, \mathrm{Zr}^{4+}: \mathrm{O}^{2-}}^{\mathrm{L}},
\end{aligned}
$$

where, for example, ${ }^{\circ} G_{\mathrm{Nd}^{3+}: \mathrm{O}^{2-}}^{\mathrm{L}}$ denotes the Gibbs energy of formation of a hypothetical liquid $\left(\mathrm{Nd}^{3+}\right)_{\mathrm{P}}\left(\mathrm{O}^{2-}\right)_{\mathrm{Q}}$. The

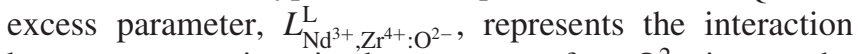
between two cations in the presence of an $\mathrm{O}^{2-}$ ion on the anion sublattice. The temperature dependency of the parameters is taken into account in accordance with eq. (5).

\subsubsection{Binary compounds}

Zirconia has three stable phases. The low-temperature phase, $\mathrm{m}-\mathrm{ZrO}_{2}$, has a monoclinic crystal symmetry, while the intermediate-temperature phase, $\mathrm{t}-\mathrm{ZrO}_{2}$, crystallizes in a 
Table 2 Evaluated thermodynamic parameters for the $\mathrm{ZrO}_{2}-\mathrm{Nd}_{2} \mathrm{O}_{3}$ system.

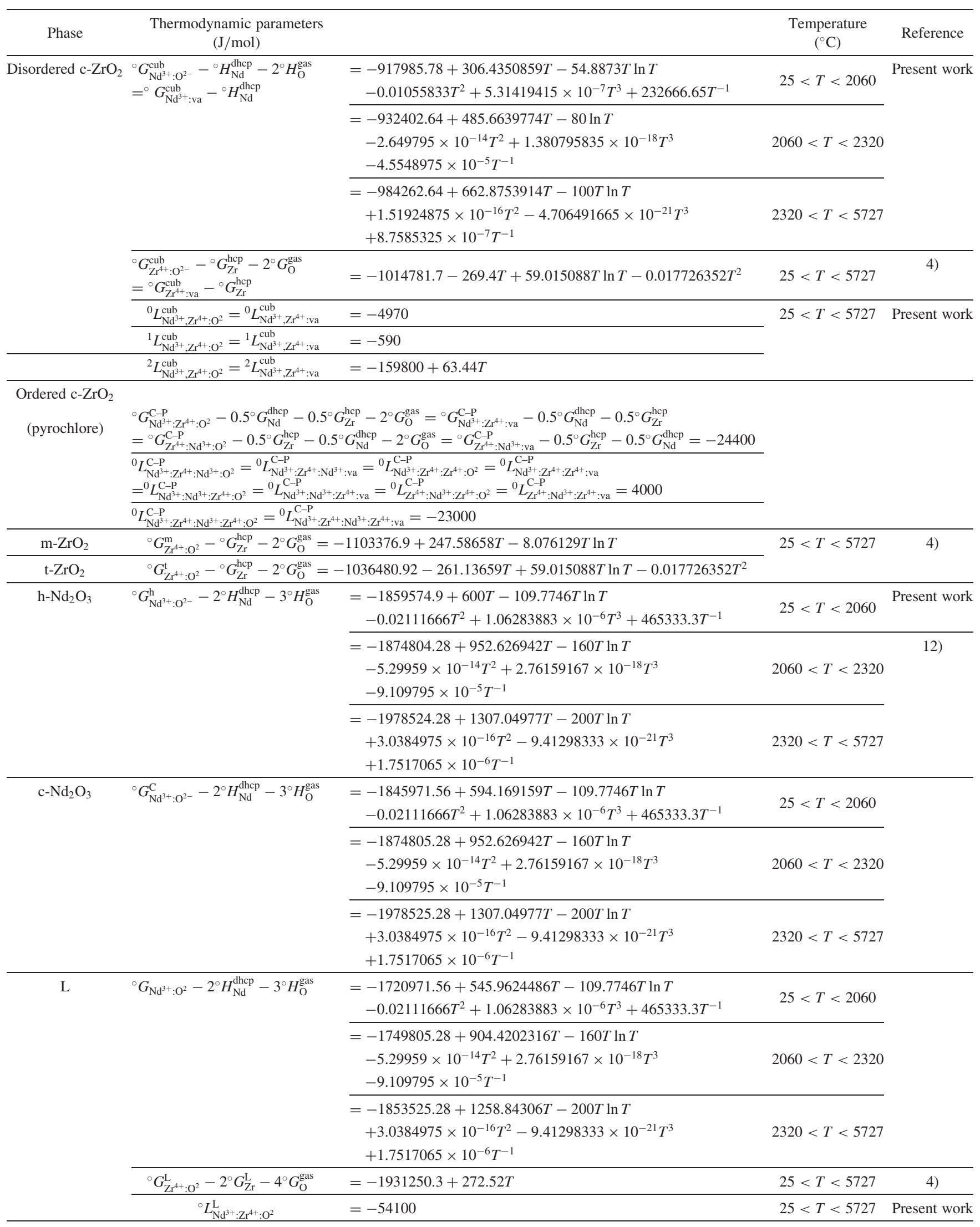

tetragonal form. The high-temperature phase is cubic $\mathrm{ZrO}_{2}$, whose Gibbs energy formalism was described in Section 2.2.1. The transition from $\mathrm{c}-\mathrm{Nd}_{2} \mathrm{O}_{3}$ to $\mathrm{h}-\mathrm{Nd}_{2} \mathrm{O}_{3}$ has been reported, ${ }^{10)}$ but its stability region in the $\mathrm{Nd}-\mathrm{O}$ binary phase diagram is still unknown. ${ }^{11,12)}$

These binary compounds were all described as being stoichiometric solid phases. The molar Gibbs energy of these phases, denoted by the superscript $\phi$, is expressed as follows: 


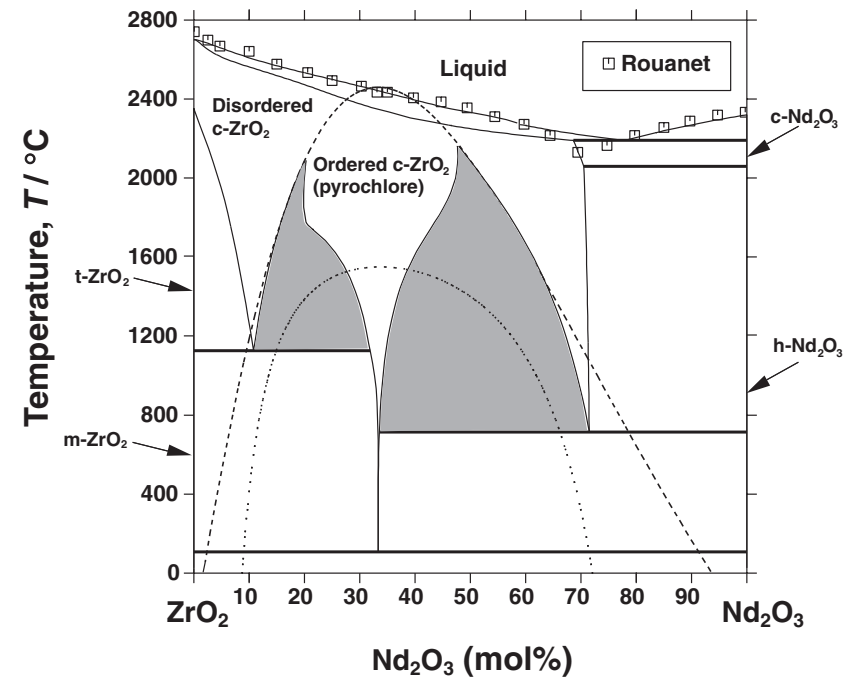

Fig. 6 Calculated $\mathrm{ZrO}_{2}-\mathrm{Nd}_{2} \mathrm{O}_{3}$ phase diagram. The dashed line denotes the secondary order-disorder transition boundary, while the dotted line shows the secondary order-disorder transition boundary.

$$
\begin{aligned}
{ }^{\circ} G^{\phi}-H^{\mathrm{ref}}= & A+B T+C T \ln T+D T^{2} \\
& +E T^{3}+F T^{7}+I T^{-1}+J T^{-9},
\end{aligned}
$$

where $H^{\text {ref }}$ is an abbreviation of $\Sigma x_{\mathrm{i}} H_{\mathrm{i}}^{\text {ref }}$.

\section{Results and Discussion}

\subsection{Phase diagram calculations}

The evaluated thermodynamic parameters for the $\mathrm{ZrO}_{2}-$ $\mathrm{Nd}_{2} \mathrm{O}_{3}$ system are shown in Table 2. Figure 6 shows the calculated $\mathrm{ZrO}_{2}-\mathrm{Nd}_{2} \mathrm{O}_{3}$ phase diagram. The shaded region of the diagram shows the two-phase separation between disordered cubic $\mathrm{ZrO}_{2}$ and the ordered cubic pyrochloretype $\mathrm{Nd}_{2} \mathrm{Zr}_{2} \mathrm{O}_{7}$ phase. The experimental points for the liquidus curve ${ }^{1)}$ are represented by the square symbols in the figure. The unique feature of this phase diagram is reproduced well in our calculations. The dashed line denotes the secondary order-disorder transition boundary, which apparently inflects the location of the liquidus curve. Our thermodynamic analysis strongly suggests that the characteristic shape of the two-phase region of interest is due to the phase separation between the fluorite and pyrochlore structures, accompanied by a cation ordering of the $\mathrm{Zr}^{4+}$ and $\mathrm{Nd}^{3+}$ ions. This behavior is clearly illustrated by the Gibbs energycomposition diagram at $T=1127^{\circ} \mathrm{C}$ shown in Fig. 7. The formation energy estimated by Knacke et $a l .{ }^{5)}$ is denoted by the open circle in the figure. The upper curve denotes the Gibbs energy of the disordered state of the cubic phase, while the lower curve denotes the Gibbs energy of the ordered state. The difference between the two lines corresponds to the ordering energy that accompanies cation arrangement. From the Gibbs energy of the disordered cubic phase, a metastable phase separation in the disordered state is expected, and the calculated miscibility gap is denoted by the dotted lines in Fig. 6. $1127^{\circ} \mathrm{C}$

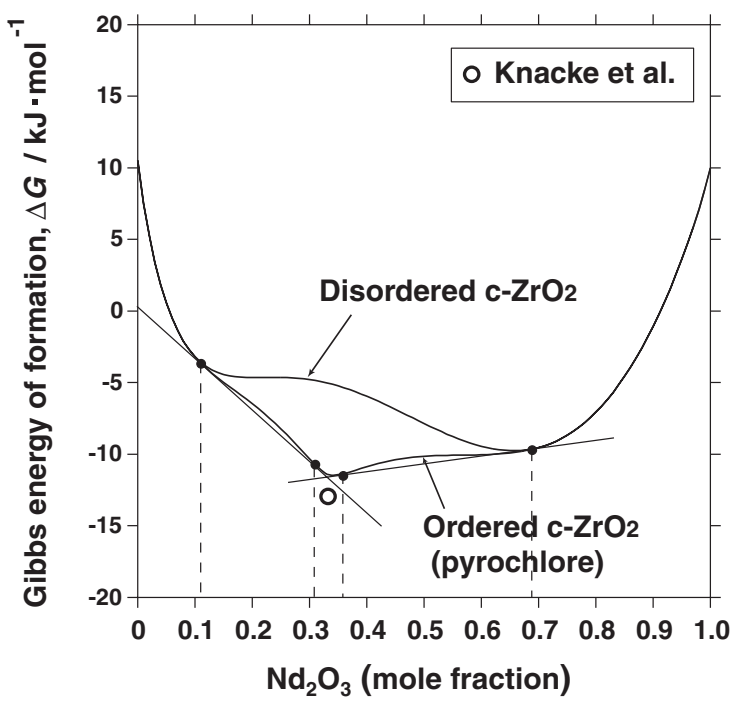

Fig. 7 Gibbs energy-composition diagram at $T=1127^{\circ} \mathrm{C}$. The upper curve denotes the Gibbs energy of the disordered state, while the lower curve denotes that of the ordered state.

\subsection{Two-phase separation accompanied by cation order- ing}

Within the Bragg-Williams-Gorsky (BWG) approximation, Büth and Inden $^{7)}$ determined the most stable atomic configuration of fcc solid solutions using a constraint of eight sublattices, dependent on the interchange energies between the first and second nearest neighbors, $\mathrm{W}^{(1)}$ and $\mathrm{W}^{(2)}$. The calculations of Büth and Inden are summarized in the ground state diagram shown in Fig. 8. The interchange energy, $\mathrm{W}^{(\mathrm{k})}=2 \mathrm{~V}_{\mathrm{AB}}^{(\mathrm{k})}-\mathrm{V}_{\mathrm{AA}}^{(\mathrm{k})}-\mathrm{V}_{\mathrm{BB}}^{(\mathrm{k})}$, where $\mathrm{V}_{\mathrm{ij}}^{(\mathrm{k})}$ is the pairwise interaction, was defined to be negative for ordering, and positive for segregation. According to the calculations of Büth and Inden, the miscibility gap between the Fm $3 \mathrm{~m}$ and $\mathrm{Fd} \overline{3} \mathrm{~m}$ space groups occurs when $\mathrm{W}^{(1)}>0$ and $\mathrm{W}^{(2)}<$ $-\mathrm{W}^{(1)}$.

We attempted to extract these interchange energies from the evaluated parameters listed in Table 2, and compare the results with the data shown in Fig. 8, irrespective of how the compound energy formalism employed in our study coincided with the BWG approximation. On the cation sublattice in the pyrochlore structure, as shown in Fig. 9, the coordination number of the first nearest neighbor ( $1 \mathrm{nn})$ pairs was 12 , while that of the second nearest neighbor ( $2 \mathrm{nn})$ sites was six, since the sublattice is an fcc array. It can then be seen that the number of $1 \mathrm{nn}$ pairs between unlike cations is six when the structure is perfectly ordered in a pyrochlore arrangement, while that of the $2 \mathrm{nn}$ pairs composed of opposite cations is also six. The formation energy, ${ }^{\circ} G_{\mathrm{Nd}^{3+}: \mathrm{Zr}^{4+}: \mathrm{O}^{2-}}^{\mathrm{C}-\mathrm{P}}$ $\left(={ }^{\circ} G_{\mathrm{Zr}^{+}+\mathrm{Nd}^{3+}: \mathrm{O}^{2-}}^{\mathrm{C}}={ }^{\circ} G_{\mathrm{Nd}^{3+}: \mathrm{Zr}^{4+}: \mathrm{va}}^{\mathrm{C}}={ }^{\circ} G_{\mathrm{Zr}^{4+}: \mathrm{Nd}^{3+}: \mathrm{va}}^{\mathrm{CP}}\right)$, in eq. (6) could thus be described using $\mathrm{W}^{(1)}$ and $\mathrm{W}^{(2)}$ as follows:

$$
\begin{aligned}
& { }^{\circ} G_{\mathrm{Nd}^{3+}: \mathrm{Zr}^{4+}: \mathrm{O}^{2-}}^{\mathrm{C}-}-0.5^{\circ} H_{\mathrm{Nd}}^{\mathrm{dhcp}}-0.5^{\circ} H_{\mathrm{Zr}}^{\mathrm{hcp}}-2^{\circ} H_{\mathrm{O}}^{\mathrm{gas}} \\
& \quad=6 \mathrm{~W}^{(1)}+6 \mathrm{~W}^{(2)} .
\end{aligned}
$$

For the regular solution interaction parameter shown in eq. (6), the number of pairs between unlike cations varies 


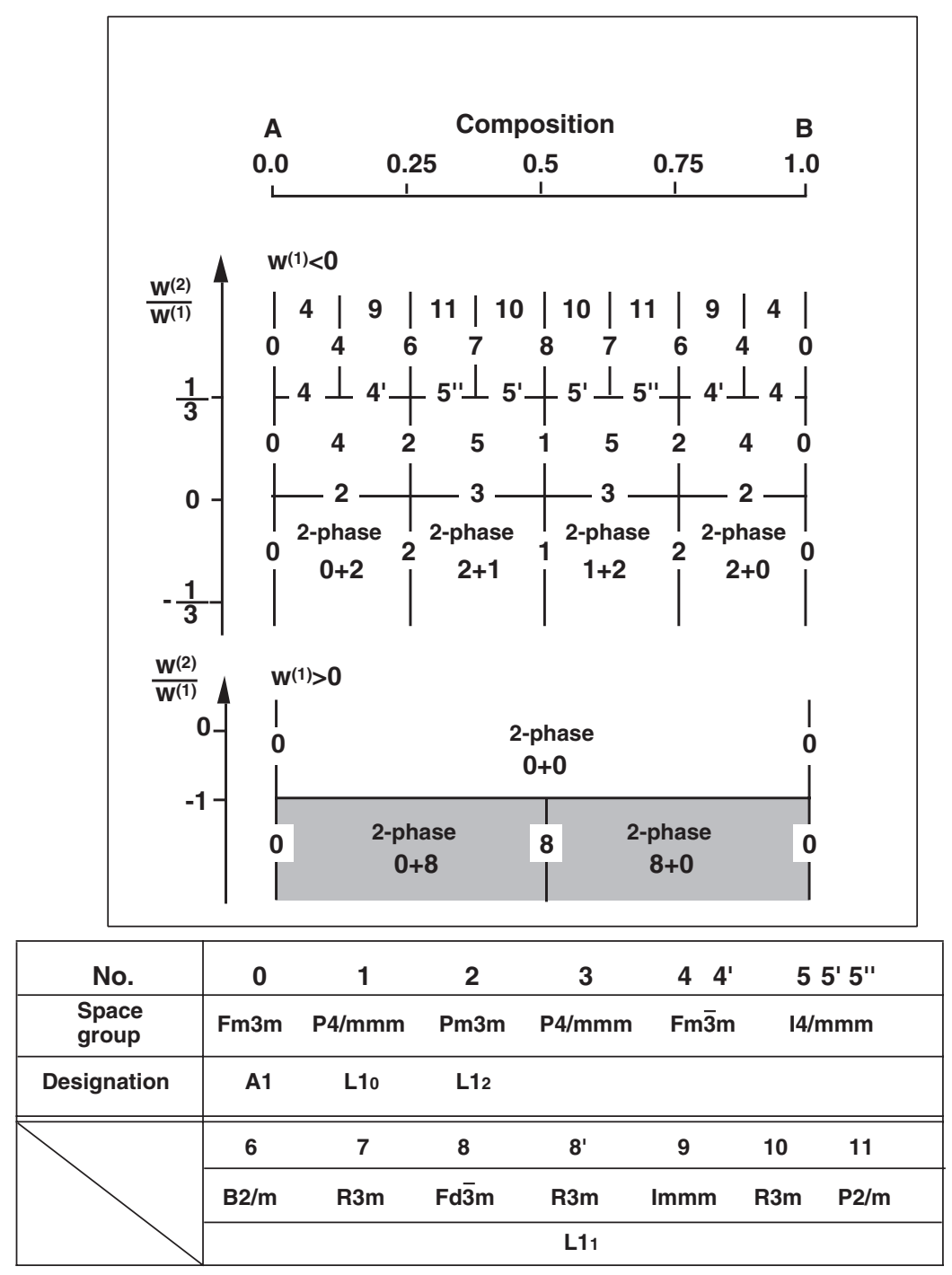

Fig. 8 Ground state diagram of fcc solid solutions with first and second nearest neighbor interactions.
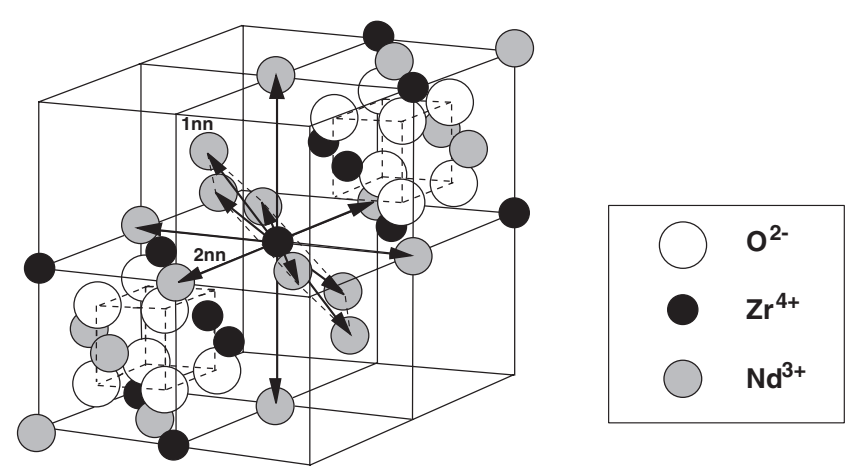

Fig. 9 Atomic configuration of the pyrochlore structure, showing the two types of octants.

with the composition. However, the probability of finding an opposite cation within a distance of $1 \mathrm{nn}$ and $2 \mathrm{nn}$ is 0.25 , at most. Thus, the following equation holds for the above parameters:

$$
L_{\mathrm{Nd}^{3+}, \mathrm{Zr}^{4+}: *: *}^{\mathrm{C}-\mathrm{P}}=L_{*: \mathrm{Nd}^{3+}, \mathrm{Zr}^{4+}: *}^{\mathrm{C}-\mathrm{P}}=3 \mathrm{~W}^{(1)}+1.5 \mathrm{~W}^{(2)} .
$$

The reciprocal parameter, $L_{\mathrm{Nd}^{3+}, \mathrm{Zr}^{4+}: \mathrm{Nd}^{3+}, \mathrm{Zr}^{4+}: *}^{\mathrm{C}}$, can be excluded, as the contribution of the pairwise interaction to the parameter is negligible. When the evaluated values listed in Table 2 are applied to eqs. (10) and (11), $\mathrm{W}^{(1)}$ and $\mathrm{W}^{(2)}$ can be evaluated as $6.7 \mathrm{~kJ} / \mathrm{mol}$ and $-10.8 \mathrm{~kJ} / \mathrm{mol}$, respectively. This fulfills the condition of $\mathrm{W}^{(1)}>0$ and $\mathrm{W}^{(2)}<$ $-\mathrm{W}^{(1)}$ for the miscibility gap between the Fm $3 \mathrm{~m}$ and $\mathrm{Fd} \overline{3} \mathrm{~m}$ space groups, and consequently, a repulsive $1 \mathrm{nn}$ interaction and an attractive $2 \mathrm{nn}$ interaction occurs between unlike cations, which is essential for a two-phase separation of the cubic structure accompanied by cation ordering.

In this work, the ordering of $\mathrm{O}^{2-}$ ions and the vacancies on the anion sublattice were not considered. Figure 10 shows the arrangement of the $\mathrm{O}^{2-}$ ions in the pyrochlore structure. Some long-range ordering pattern can be observed in this configuration. However, the oxygen anions diffuse at a rate that is many orders of magnitude faster than the cations in this type of solid electrolyte. Therefore, the cation arrangement is the rate-determining process for the ordering of the cubic $\mathrm{ZrO}_{2}$ phase, and the $\mathrm{O}^{2-}$ ion array provides the best possible response to the cation array. 

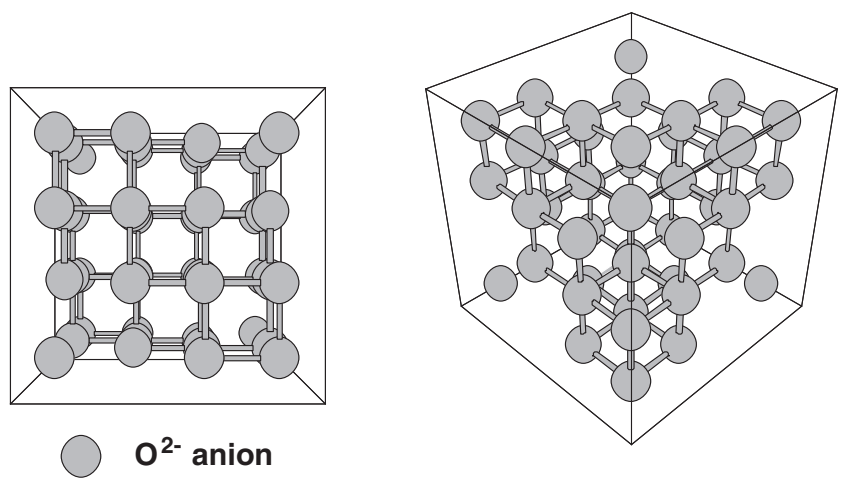

Fig. 10 Oxygen anion and vacancy arrangement in the pyrochlore structure.

\section{Conclusions}

(1) The two-phase equilibrium between the cubic zirconia phase and the pyrochlore phase in the $\mathrm{ZrO}_{2}-\mathrm{Nd}_{2} \mathrm{O}_{3}$ pseudo-binary system was analyzed using split compound energy formalism. The calculated results suggest that the characteristic shape of the two-phase region of interest is due to the phase separation between the fluorite and pyrochlore structures, accompanied by an ordering of the tetravalent zirconium ions and trivalent neodymium ions on the cation sublattices.

(2) Thermodynamic analysis indicates that the repulsive $1 \mathrm{nn}$ and attractive $2 \mathrm{nn}$ interactions play important roles in the characteristic isolated two-phase region of this system. The long-range ordering of the $\mathrm{O}^{2-}$ ions and the vacancies is the best possible response to the cation array.

\section{Acknowledgements}

The authors wish to gratefully acknowledge the valuable support of Ms. Reiko Iwasaki at Tohoku University, Japan.

\section{REFERENCES}

1) A. Rouanet: Rev. Int. Hautes Tempèr. et Rèfract. 8 (1971) 161-180.

2) F. H. Brown Jr. and P. Duwez: J. Am. Ceram. Soc. 38 (1955) 95-101.

3) R. Khanna, T. R. Welberry and R. L. Withers: J. Phys. Condens. Matter. 5 (1993) 4251-4262.

4) P. Liang, N. Dupin, S. G. Fries, H. J. Seifert, I. Ansara, H. L. Lukas and F. Aldinger: Z. Metallkd. 92 (2001) 747-756.

5) Thermochemical Properties of Inorganic Substances, 2nd Ed., eds. O. Knacke, O. Kubaschewski and K. Hesselmann, (Springer-Verlag, Berlin, 1991) p. 1437.

6) A. T. Dinsdale: Calphad 15 (1991) 317-425.

7) J. Büth and G. Inden: Acta Metal. 30 (1982) 213-224.

8) I. Ansara, B. Sundman and P. Willemin: Acta Metal. 36 (1988) 977982.

9) M. Hillert, B. Jansson, B. Sundman and J. Ågren: Metall. Trans. A 16A (1985) 261-266.

10) P. Villars: Pearson's Handbook, Desk Edition, Crystallographic Data for Intermetallic Phases, (ASM International, Materials Park, Ohio, USA, 1997), vol. 2, 2492-2493.

11) Binary Alloy Phase Diagrams, 2nd Ed., eds. T. B. Massalski, H. Okamoto, P. R. Subramanian and L. Kacprzak, (ASM International, Materials Park, Ohio, USA, 1990), vol. 3, 2790-2792.

12) The SGTE Substance Database, Version 1994. Scientific Group Thermodata Europe (SGTE), Grenoble (1994). 